\begin{tabular}{|l|l|}
\hline SEP 31996 ENGINEERING DATA TRANSMITTAL & Page 1 of $\frac{1}{1 . \text { EDT } \quad 142246}$ \\
\hline Sta. $3720 \mathrm{kE}$
\end{tabular}

2. To: (Receiving Organization) Consequence Analysis

5. Proj./Prog./Dept.10iv.:

TWRS FSAR
3. From: (Originating Organizetion) Consequence Analysis (8M400)

6. Design Authority/ Design Agent/Cog. Enar.:

M. V. Shultz
8. Originstor Remerks:

Approval and Release of Calculation Note in support of Flammable Gas Analysis for TWRS FSAR and BIO. This document is not to be used as the sole basis to authorize activities or to change authorization, safety or design bases.

11. Receiver Remarks: 11A. Design Baseline Document? [] Yes [X] No

4. Related EDT NO.:

N/A

7. Purchase Order No.:

N/A

9. Equip./Component No.: $N / A$

10. System/Bldg-/Facility:

$N / A$

12. Major Assm. Dwg. No.: N/A

13. Permit/Permit Application No.: N/A

14. Required Response Date:

$N / A$

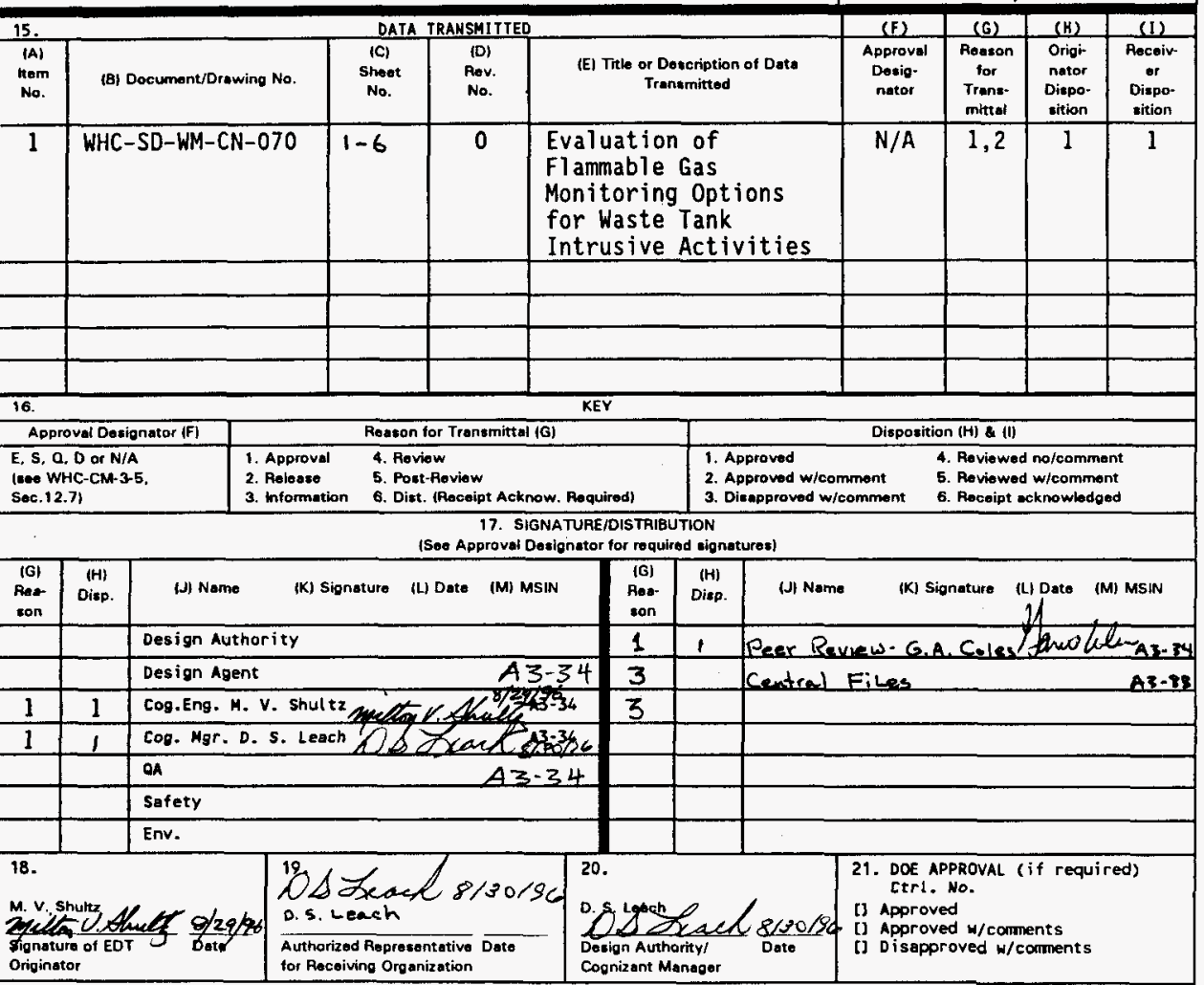




\title{
Evaluation of Flammable Gas Monitoring Options for Waste Tank Intrusive Activities
}

\author{
N. V. Shultz
}

Westinghouse Hanford Company, Richland, WA 99352

U.S. Department of Energy Contract DE-AC06-87RL10930
EDT/ECN: 142246
UC: 610
Org Code: $8 M 400$
Charge Code: N2158
B\&R Code: EW3120072
Total Pages: 6

Key Words: Flammable-Gas Monitor, Failure Rate, Intrusive Activity

Abstract: This calc note documents an evaluation of three options for monitoring hydrogen during waste tank intrusive activities. The three options are 1) one Combustible Gas Monitor with an operator monitoring the readout, 2) two CGMs with separate operators monitoring each gas monitor, and 3) one CGM with audible alarm, no dedicated operator monitoring readout. A comparison of the failure probabilities of the three options is provided. This Calculation Note supports the Flammable Gas Analysis for TWRS FSAR and BIO. This document is not to be used as the sole basis to authorize activities or to change authorization, safety or design bases.

TRADEMARK DISCLAIMER. Reference herein to any specific comercial product, process, or service by trade name, trademark, manufacturer, or otherwise, does not necessarily constitute or imply its endorsement, recomendation, or favoring by the United States Government or any agency thereof or its contractors or subcontractors.

Printed in the United States of America. To obtain copies of this document, contact: WHC/BCS Document Control Services, P.O. Box 1970, Mailstop H6-08, Richland WA 99352, Phone (509) 372-2420; Fax (509) $376-4989$.
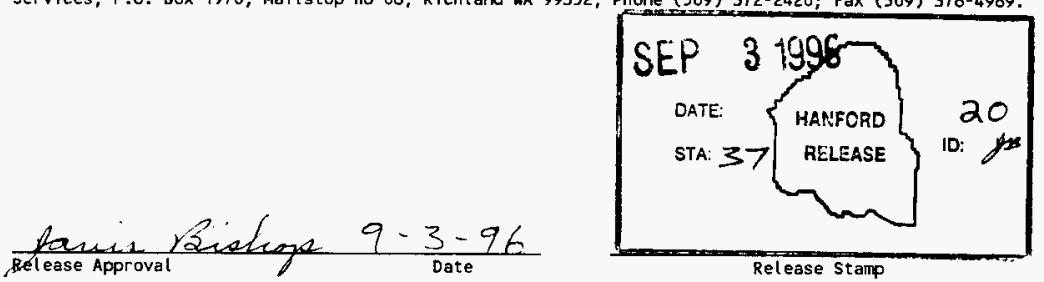

\section{Approved for Public Release}


WHC-SD-WM-CN-070, Rev. 0

\section{EVALUATION OF FLAMMABLE GAS MONITORING OPTIONS FOR WASTE TANK INTRUSIVE ACTIVITIES}

\section{INTRODUCTION AND PURPOSE}

Recommendations for hydrogen monitoring during intrusive activities in waste tanks contained in safety evaluation documentation specify that two independent monitoring systems be used. This calculation note provides an evaluation of the reliability of various monitoring schemes. Three schemes will be evaluated. They are:

1. One Combustible Gas Monitor (CGM) with an operator monitoring the readout,

2. Two CGMs with separate operators monitoring each gas monitor readout, and

3. One CGM with audible alarm.

\section{METHODOLOGY}

This evaluation is based on commonly accepted Probabilistic Risk Assessment practices. The comparison of the various monitoring options is done on the basis of estimated failure probability for a 48 hour mission time.

Calculation of failure probabilities includes random failures and common cause considerations.

\section{ASSUMPTIONS}

Specific failure rate data for the CGM is not available. However, an analysis of the Standard Hydrogen Monitoring System (SHMS) (Lindberg, 1995) gives an overall failure probability of $5.16 \times 10^{-06}$ for a mission time of four days (1.08 $\times 10^{-8}$ per hour). This probability is indicative of a well designed system. A survey of the failure rate information in the Instruments, Controls, \& Sensors portion of IEEE 500 shows that the rates for such instrumentation vary between approximately $1 \times 10^{-7}$ and $1 \times 10^{-5}$ per hour. If it is assumed that the failure rate of $1 \times 10^{-6}$ per hour then this yields an overall failure probability of $4.8 \times 10^{-5}$ for a 4 day mission..

Normally, it is necessary to take into account the mean time to repair when evaluating the overall reliability of a system. It is assumed for the CGM that when a failure is identified work is immediately stopped and a new CGM is obtained. Since these are portable instruments, the amount of time required to obtain a new one is considered negligible (therefore the mean time to repair is negligible). It is al so assumed that the failure rate of the CGM with audible alarm is essentially the same as the basic failure rate. The failure rate of personnel to perform the proper actions upon hearing the notification of the operator monitoring the CGM or hearing the alarm is assumed negligible.

There are many concerns addressed in Human Reliability Analysis (HRA). In the case of this evaluation, it is assumed that the failure of the operator to correctly interpret a CGM indication dominates all other HRA concerns. The failure rate of the operator for reading the CGM correctly is assumed to be 0.001 . This is based on NUREG/CR-1278-F human error rates for "Check Reading 
WHC-SD-WM-CN-070, Rev. 0

Display Activities" for digital readouts. It is assumed that normal stress conditions exist for this activity. It should be noted that the assumed failure rate may be even greater than assumed here. This is because in the case of reading the CGM additional possibilities for error exist since the readout value is not the actual hydrogen concentration. To obtain actual concentration a multiplier has to be used. If an error is made in applying the multiplier or the wrong multiplier is used then an undesirable condition may not be detected. It should also be noted that personnel that are required to constantly monitor a non-alarming readout for long periods of time may loose mental acuity and also have failure rates higher than indicated in NUREG/CR-1278-F.

For configurations where two operators and two CGMs are used, common cause conditions are assumed to exist. This is because the CGMs are assumed to be the same model, use the same calibration procedures, are calibrated by the same person, the operators that read the CGMs have common training, and the location of the meters places them under common conditions.

Common cause is often stated in terms of beta factor. Beta factor is the fraction of the total failure rate attributable to dependent failures. NUREG 1150 provides a discussion of beta factors as well as a table of generic beta factors. In the case of two operators and two CGMs, there are two common cause situations, one for the instrumentation, and one for the operators. The failure rate for independent failures is essentially the product of the two failure rates. The common cause failure rate is defined as:

(beta/(1-beta)) $\times($ failure rate)

The overall failure rate is the sum of the independent failure rate and the common cause faiTure rate. Beta factors in NUREG 1150 generally range from $1 \times 10^{-2}$ to $1 \times 10^{-1}$. For this evaluation, it is assumed that the beta factor is 0.1 .

\section{ANALYSIS AND RESULTS}

Since the purpose of this evaluation is to provide a comparison of the three options, the mission time is set at 48 hours. The overall failure probabilities of the various configurations of the flammable gas monitoring systems are as follows. Each of these failure probabilities assumes no repair. Since the failure rates are small, the simplified equation of faiture rate times mission time is used. All operator required actions are assumed to be for a single demand during the mission time.

1. For one CGM and one operator constantly monitoring the CGM the failure probability is essentially the failure rate of the operator

$$
\begin{array}{ll}
4.8 \times 10^{-5}- & \begin{array}{l}
\text { Probability instrument fails during the mission } \\
1 \times 10^{-3}-
\end{array} \\
\text { HRA probability of operator failing to correctly } \\
\text { read instrument when required. }
\end{array}
$$

\subsection{5 - Total probability of instrument or operator failing}

2. For two CGMs and two operators constantly monitoring the CGMs, the failure 
probability is the independent failure probability of two CGMs plus the common cause failure probability of two operators
$\left(4.8 \times 10^{-5}\right)^{2}-$
Probability that both CGMs fail
$(0.1 / 1-0.1) \times\left(4.8 \times 10^{-5}\right)^{5}-$ Common cause probability that both
$(0.001)^{2}-$
CGMs fail simultaneously
$(0.1 / 1-0.1) \times 0.001-$
Probability that both operators will fail to read the CGMs correctly
$1.11 \times 10^{-4}-$
Common cause probability that both
operators fail to read the CGMs correctly
Total probability of common cause
and random failures

3. For one CGM with Audible alarm the failure probability is $4.8 \times 10^{-5}$.

\section{CONCLUSIONS}

Use of an operator to monitor the fiammable gas concentration in a waste tank during intrusive activities results in a high probability of failure to detect an unacceptable concentration of hydrogen. This is because the probability of human error is much higher than the random failure probability of instrumentation. Adding a second CGM and operator reduces the failure probability to a lower value, but is high because the human factor is still present along with common cause due to identical redundant systems.

Configuring a CGM to operate an alarm provides the lowest failure probability by eliminating the human factor.

If instrument reliability is actually higher, which may be the case, and human reliability is even lower, which most likely is the case, then the conclusions will still be the same. In fact, such a situation makes an even stronger case for the CGM with an alarm function.

\section{RECOMMENDATIONS}

Using a CGM with an alarm appears to be the most cost effective approach to monitoring for flammable gas during intrusive activities in a waste tank. If concern exists about the CGM failing while not attended, a requirement for periodic reading of the CGM indication could be established. If a very high reliability is desired, use of the existing SHMS system (where present) coupled with a CGM with alarm should be considered. 


\section{REFERENCES}

IEEE 500-1984, IEEE Guide to the Collection and Presentation of Electrical, Electronic, Sensing Component, and Mechanical Equipment Reliability Data for Nuclear-Power generating Stations, The Institute of Electrical and Electronics Engineers, Inc., New York, New York

Lindberg, S. E., 1995, Standard Hydrogen Monitoring System Cabinet Ana7ysis, (Internal letter 8M400-SEL-05006 to R. J. Van Vleet and T. C. Schneider, June 12, 1995), Westinghouse Hanford Company, Richland, Washington.

NUREG/CR-1278-F, 1983, Handbook of Human Reliability Analysis With Emphasis on Nuclear Power Plant Applications, Sandia National Laboratories, Albuquerque, New Mexico

NUREG 1150, Reactor Risk Reference Document, February 1987 
PEER REVIEW CHECKLIST

WHC-SD-WM-CN-070, Rev. 0

Document Reviewed: EVALUATION OF FLAMMABLE GAS MONITORING OPTIONS FOR WASTE TANK INTRUSIVE ACTIVITIES

Author:

Milton Shultz

Date:

AUGUST 29, 1996

Scope of Review: Content and Technical Adequacy

Yes No NA

H[] []

[][][15

Y[][]

[] [][4

[?] []

Y Y [ ] []

[][] [ [

[] [] [ [

[][][i广

[] [] $3 \mathrm{H}^{2}$

[]] ] [ 54

[] [ ] [4

[I] [I

$M[][]$

H[][]

И[][]

[1][]
Problem completely defined.

Accident scenarios developed in a clear and logical manner.

Necessary assumptions explicitly stated and supported.

Computer codes and data files documented.

Data used in calculations explicitly stated in document.

Data checked for consistency with original source information as applicable.

Mathematical derivations checked including dimensional consistency of results.

Models appropriate and used within range of validity or use outside range of established validity justified.

Hand calculations checked for errors. Spreadsheet results should be treated exactly the same as hand calculations.

Software input correct and consistent with document reviewed.

Software output consistent with input and with results reported in document reviewed

Limits/criteria/guidelines applied to analysis results are appropriate and referenced.

Limits/criteria/guidelines checked against references.

Safety margins consistent with good engineering practices.

Conclusions consistent with analytical results and applicable limits.

Results and conclusions address all points required in the problem statement.

Review calculations, comments, and/or notes are attached.

COMMENTS:

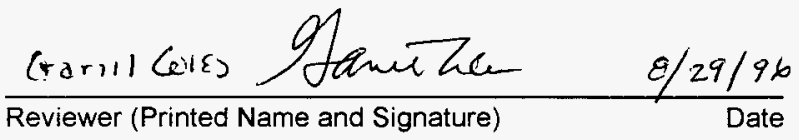

